\title{
FEIÇÕES CRUSTAIS DETERMINADAS PELA ANÁLISE AZIMUTAL DA FUNÇÃO DO RECEPTOR, NA REGIÃO DA ESTAÇÃO SISMOLÓGICA DE RIO CLARO (RCLB)
}

\author{
João Carlos Dourado ${ }^{1}$, Marcelo Assumpção², Walter Malagutti Filho ${ }^{3}$ \\ e Marcelo Belentani de Bianchi ${ }^{4}$ \\ Recebido em 18 abril, 2006 / Aceito em 30 maio, 2007 \\ Received on April 18, 2006 / Accepted on May 30, 2007
}

\begin{abstract}
This paper presents an analysis of receiver functions to estimate crustal structure beneath the Rio Claro Seismological Station, which has been in operation since October 2002. The depths obtained for the Moho discontinuity range from 36 to $44 \mathrm{~km}$. A systematic variation of Moho depths with azimuth was observed. Larger values were obtained with events arriving from the North and the values of $36 \mathrm{~km}$ were observed with teleseisms arriving from the SW. This result shows that in the region there is an elevation of the Moho discontinuity near the Domo de Pitanga structural high. This result probably indicates a tectonic origin for this structure caused by deep deformation processes involving the whole lithosphere.
\end{abstract}

Keywords: receiver function, crustal features, Domo de Pitanga, azimuthal variation.

RESUMO. Este trabalho apresenta a interpretação da função do receptor determinada para os eventos registrados na Estação Sismológica de Rio Claro, em operação desde outubro de 2002. As profundidades calculadas para a Moho variaram de 36 a $44 \mathrm{~km}$. A análise da variação dos valores de profundidade mostra que eles estão associados aos azimutes dos eventos. Portanto decidiu-se fazer uma análise azimutal dos resultados obtidos. Os maiores valores foram calculados para eventos que se localizam à norte da estação e os valores de $36 \mathrm{~km}$ foram calculados para telessismos do quadrante SW. Estes resultados mostram que existe uma elevação da Moho na direção da estrutura "Domo de Pitanga". Estes resultados indicam que esta estrutura é provavelmente de origem tectônica e causada por eventos profundos do manto superior.

Palavras-chave: função do receptor, feições crustais, Domo de Pitanga, variação azimutal.

\footnotetext{
${ }_{1}^{1}$ Departamento de Geologia Aplicada, IGCE, UNESP, Campus de Rio Claro, Av. 24-A, 1515, Bela Vista, Caixa Postal 178, 13506-900 Rio Claro, SP, Brasil. Tels.: (19) 3526-2848 / 3526-2803 -E-mail: jdourado@rc.unesp.br

${ }^{2}$ Departamento de Geofísica, IAG, USP, Rua do Matão, 1226, Cidade Universitária, 05508-090 São Paulo, SP, Brasil. Tel.: (11) 3091-4755 - E-mail: marcelo@iag.usp.br ${ }^{3}$ Departamento de Geologia Aplicada, IGCE, UNESP, Campus de Rio Claro, Av. 24-A, 1515, Bela Vista, Caixa Postal 178, 13506-900 Rio Claro, SP, Brasil. Tel.: (19) 3526-2841 - E-mail: malaguti@rc.unesp.br

${ }^{4}$ Departamento de Geofísica, IAG, USP, Rua do Matão, 1226, Cidade Universitária, 05508-090 São Paulo, SP, Brasil. Tel.: (11) 3091-4755
} 


\section{INTRODUÇÃO}

A Estação Sismológica de Rio Claro (RCLB) localiza-se na Floresta Estadual Edmundo Navarro de Andrade (antigo Horto Florestal), no município de Rio Claro - SP, com coordenadas geográficas: $47,53^{\circ} \mathrm{W}$ e 22,41오 (Fig. 1).

A estação é constituída por um sismômetro banda-larga fabricado pela Guralp System Ltd. (Inglaterra), modelo CMG-3ESP, com resposta plana na faixa 0,033 a $50 \mathrm{~Hz}$. 0 equipamento possui um digitalizador incorporado, que nesta fase de operação da estação está digitalizando os sismogramas com uma taxa de 100 amostras por segundos.

0 sismômetro banda-larga está instalado desde 22 de outubro de 2002, e dos registros obtidos foi determinada a função do receptor, conforme desenvolvida por Langston $(1977,1979)$.

A função do receptor (FR) é uma das ferramentas geofísicas mais utilizada para estudos mais profundos da crosta terrestre e tem apresentado dados coerentes com outros tipos de investigação sobre a profundidade da Moho. Atualmente esta técnica está sendo desenvolvida para estudos do manto superior, utilizando-se inversões conjuntas com outras técnicas geofísicas, principalmente a dispersão das ondas superficiais, como uma maneira de diminuir a ambigüidade (Julià et al., 2003).

Este estudo pretende contribuir para o conhecimento das estruturas crustais na região, que possui importantes altos estruturais com origem ainda não totalmente explicadas.

\section{GEOLOGIA DO LOCAL DA RCLB}

A cidade de Rio Claro está localizada na borda nordeste da Bacia do Paraná (Fig. 1), na feição geomorfológica denominada depressão periférica, onde afloram sedimentos com idades desde o Permiano até 0 Quaternário, depositados sobre rochas cristalinas pré-cambrianas (CPRM, 2001).

0 sismômetro está instalado diretamente sobre um afloramento de diabásio, pertencente a um sill, que faz parte da Formação Serra Geral. Neste local ele possui aproximadamente 70 metros de espessura. Estas espessuras foram determinadas por sondagens elétricas executadas durante o projeto de escolha do local adequado à implantação da estação. 0 sill se sobrepõe a sedimentos clásticos da formação Corumbataí. A espessura dos sedimentos da Bacia do Paraná neste local é estimada em 1.000 metros (Sousa, 2002).

A estação localiza-se aproximadamente $12 \mathrm{~km}$ a NE da borda aflorante do alto estrutural do Domo de Pitanga.

A gênese desta estrutura, juntamente com outros altos presentes na Depressão Periférica, não está totalmente explicada
(Sousa, 2002). No caso específico do Domo de Pitanga existe a ocorrência de sedimentos da base da coluna estratigráfica da Bacia Sedimentar do Paraná (Grupo Itararé) em meio à faixa de afloramentos da Formação Corumbataí, onde existe uma série de feições estruturais anômalas, quando comparada com 0 restante da Bacia do Paraná, esta estrutura é mostrada no mapa geológico local da Figura 2.

Sousa (1997) descreve a estrutura de Pitanga como uma feição assimétrica, com flanco oeste marcado por falhas e o flanco leste caracterizado por uma ligeira inclinação de camadas. Em seu interior ocorrem baixos intercalados, também marcados por falhas e camadas inclinadas. A autora reconheceu pelo menos três etapas para 0 desenvolvimento das falhas que formara essa estrutura; (1) falhas normais apontando para a distensão aproximada E-W, (2) falhas sindeposicionais à Formação Rio Claro com indicação de tectônica distensiva e (3) falhas que deformam a Formação Rio Claro, inversas e transcorrentes.

Segundo Assumpção et al. (2002), na área de ocorrência da Bacia do Paraná no Estado de São Paulo, a espessura crustal varia de 40 a $47 \mathrm{~km}$, com uma tendência de espessamento para 0 centro da bacia.

\section{FUNÇÃO DO RECEPTOR}

Quando uma onda elástica se propaga da fonte ao receptor ela atravessará rochas e estruturas que irão modificar as suas feições, de tal forma que, o seu registro (sismograma) em uma estação sismológica será influenciado pelo tipo de pulso da fonte (mecanismo gerador do sismo), pela resposta do equipamento de registro (tipo de sismômetro e registrador) e ainda trará consigo a "assinatura" do meio pelo qual se propagou. Este processo de interação da onda elástica com o meio no qual propaga é denominado convolução.

Quando uma frente onda P, gerada por um sismo que se localiza a uma grande distância da estação sismológica (telessismo), atinge uma interface sub-horizontal que separa meios de velocidades diferentes como, por exemplo, a Moho, parte da energia é refratada em onda S (Ps) e parte sofre reflexões múltiplas, como mostra a Figura 3.

A função do receptor é um método de análise dos registros sísmicos, desenvolvido por Langston (1977, 1979), que busca recuperar do sismograma as informações trazidas das estruturas crustais nas proximidades do sismômetro, através da deconvolução da componente horizontal pela componente vertical do sinal da onda P. Este processo evidencia todas as ondas convertidas de $\mathrm{P}$ a SV nas várias descontinuidades da 
$48^{\circ} \mathrm{W}$

$44^{\circ} \mathrm{W}$

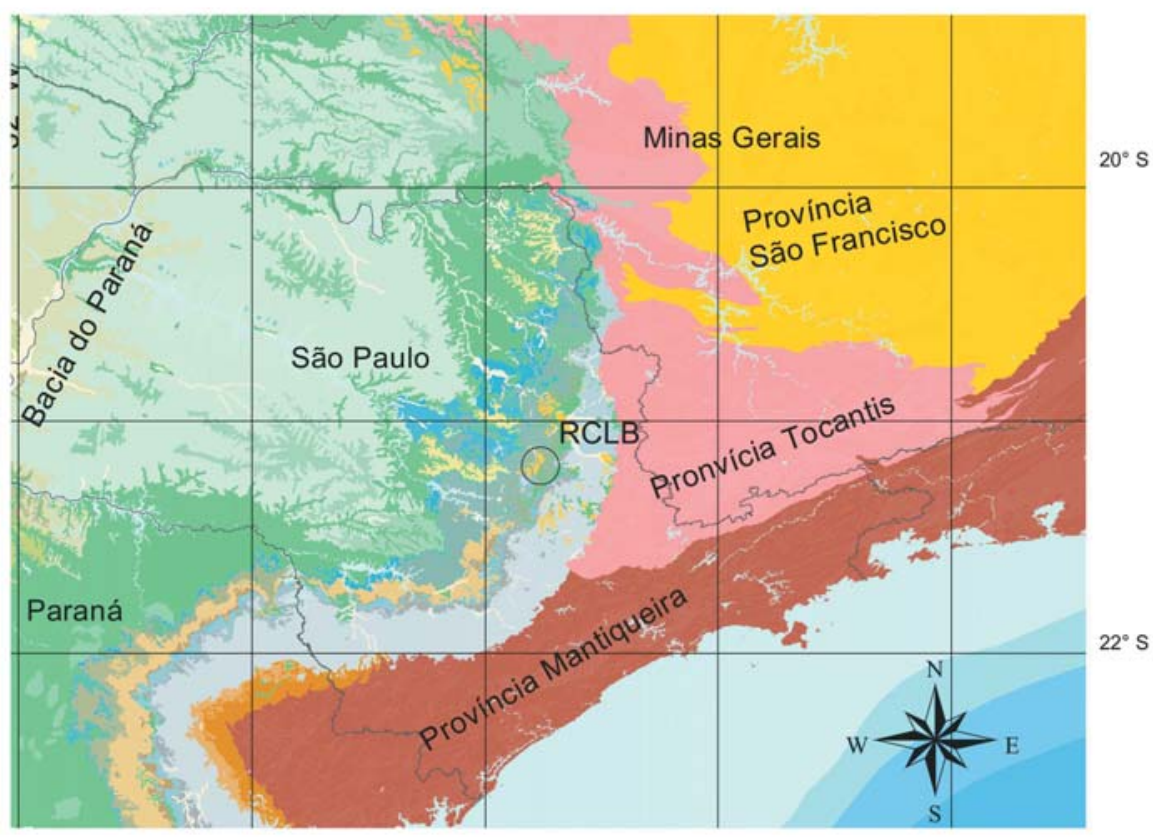

300

300

600 Kilometers

Figura 1 - Localização da Estação Sismológica RCLB, mostrando as províncias geológicas (CPRM, 2001).

\section{Geologia Local}
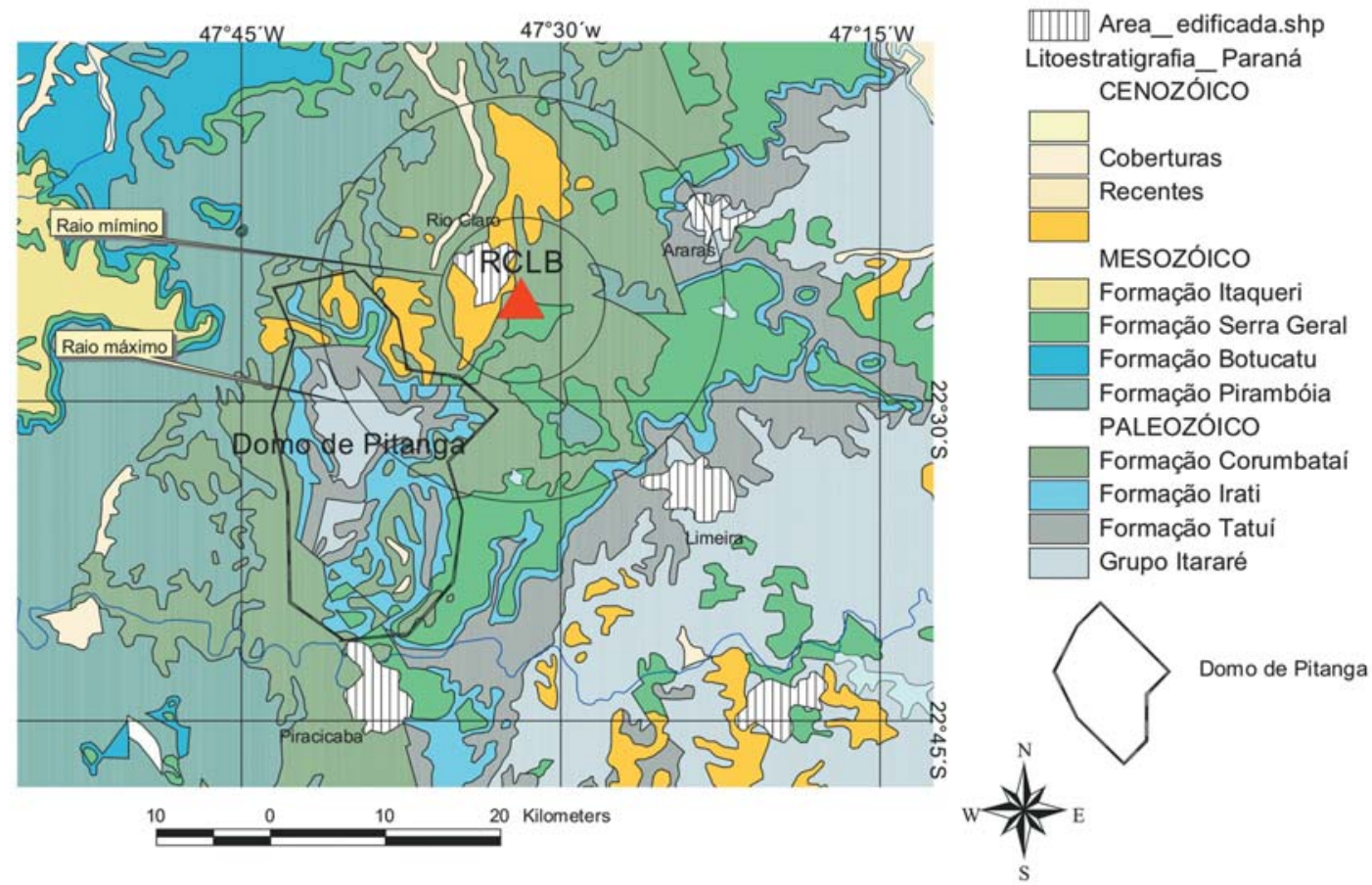

Figura 2 - Mapa geológico local mostrando em destaque a Estação Sismológica RCLB (triângulo vermelho) e a estrutura "Domo de Pitanga". 


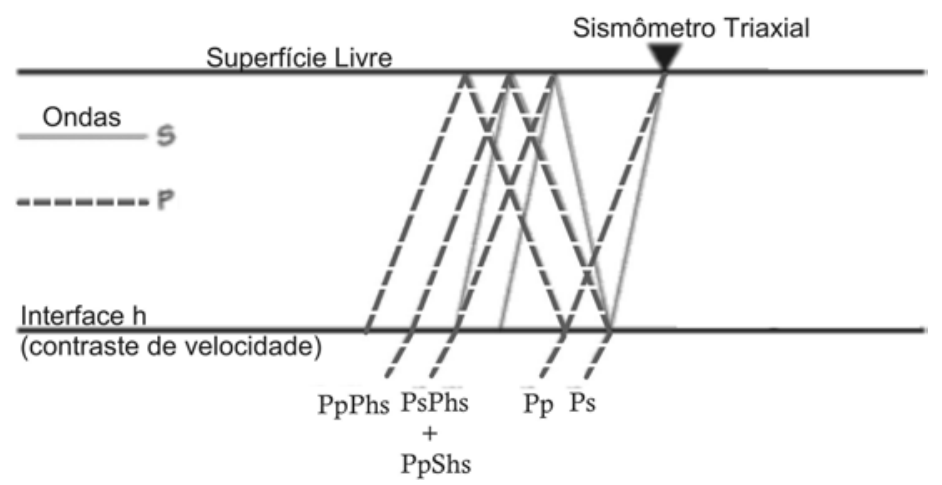

Figura 3 - Representação esquemática dos raios das ondas que atingem uma estação sismológica a partir de uma frente onda de ondas P. A nomenclatura dos raios é feita da seguinte maneira: com exceção da primeira chegada, as letras maiúsculas representam um percurso para baixo, as minúsculas para cima e a letra "h" indica a interface de reflexão. (Ammon, 1997).

crosta, principalmente da Moho, gerando uma série temporal como a mostrada na Figura 4.

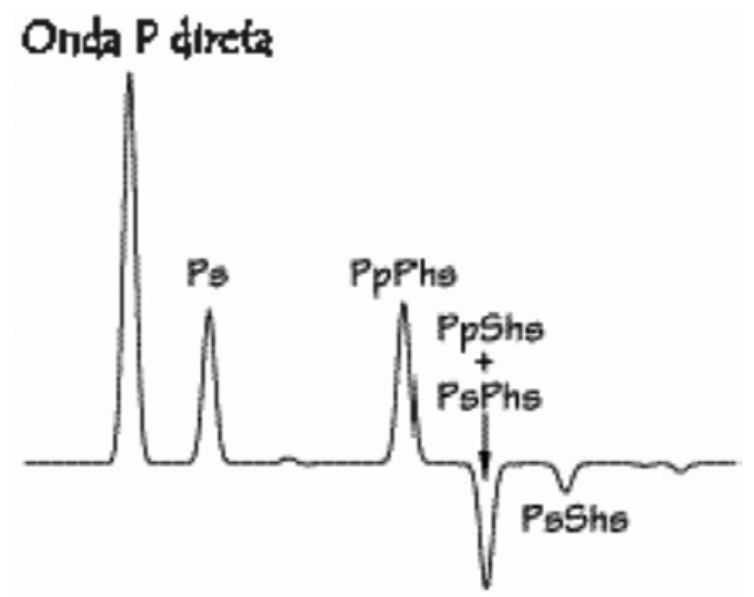

Figura 4 - Registro da função do receptor radial mostrando os picos das ondas convertidas em $\mathrm{S}$ que chegam à estação, relativas ao esquema da Fig. 3 (Ammon, 1997).

0 cálculo da função do receptor deve usar preferencialmente os telessismos com distâncias epicentrais situadas entre $30^{\circ} \mathrm{e}$ $90^{\circ}$ com relação à estação sismológica, pois nesta condição, as ondas $P$ atingem a parte inferior da crosta com um ângulo próximo da vertical tendo, portanto amplitudes maiores na componente vertical do sismômetro, enquanto que a parte de sua energia transformada em onda transversal Ps, no processo de refração nas descontinuidades sub-horizontais, terá maiores amplitudes nas componentes horizontais. Este fato faz com que no processo de deconvolução, da componente vertical com a horizontal radial, seja realçada a onda Ps, obtendo-se assim a função do receptor.
Além da distância epicentral, outro fator importante na escoIha dos telessismos para o cálculo da função do receptor é a sua magnitude, pois quanto maior a razão sinal-ruído, menor será 0 erro na determinação da Ps. Para este trabalho, um dos critérios adotados para a escolha do telessimo foi ter magnitude igual ou maior que $5 \mathrm{~m}_{\mathrm{b}}$.

\section{TRATAMENTO E ANÁLISE DOS DADOS}

Foram utilizados eventos de outubro de 2002 a abril de 2004. No total foram analisados 193 eventos com magnitude acima de $5.0 m_{b}$ e distância epicentral entre $20^{\circ}$ e $95^{\circ}$, mostrados na Figura 5.

Ressalta-se que a maioria dos autores recomenda que sejam utilizados eventos com distâncias epicentrais variando de $30^{\circ}$ a 90, para se evitar o fenômeno da triplicação que ocorre aproximadamente entre $15^{\circ}$ e $30^{\circ}$, devido a grandes aumentos repentinos de velocidades que ocorrem no manto superior. No entanto, optou-se em utilizar eventos com distâncias menores que $30^{\circ}$ para aproveitar os eventos andinos, que fornecem informações muito importantes para azimutes SW, W e NW.

Destes 193 eventos processados, 58 apresentaram boas curvas da função do receptor e foram então selecionados para análise e interpretação.

Os sismogramas foram processados utilizando as rotinas do programa SAC (Seismic Analysis Code, Lawrence Livermore National Laboratory, University of California). A função do receptor foi calculada com deconvolução no domínio da freqüência, utilizando-se rotinas de Ammon (1997).

Para cada um dos eventos foi calculada a função do receptor, utilizando-se filtro passa-baixas gaussiano de $\sim 1.4 \mathrm{~Hz}$ e um 


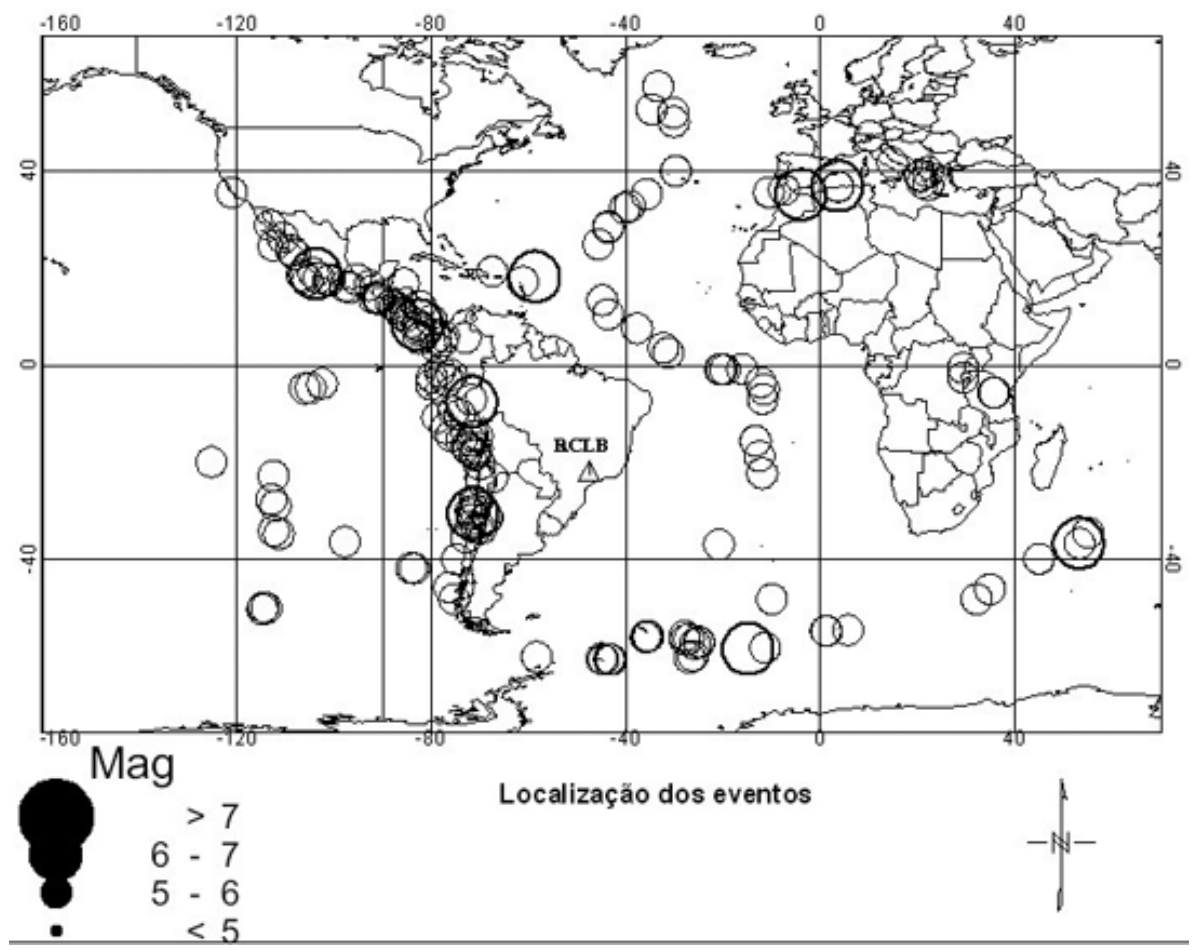

Figura 5 - Mapa mostrando a estação sismológica RCLB (triângulo) e os epicentros dos telessismos (círculos) utilizados para o cálculo da função do receptor.

nível d’água de 0.001 . Este nível é utilizado para estabilizar a deconvolução. Também foram utilizadas janelas de 55, 65, 75, 85 e 95 segundos, escolhendo-se a melhor janela para cada evento.

A Figura 6 mostra o conjunto das FRs provenientes de eventos localizados a SW da estação.

Os eventos estão ordenados de acordo com a distância epicentral indicada no lado direito do gráfico, o sinal negativo (-) localizado à esquerda deste valor indica que função do receptor não foi utilizada para análise final. 0 motivo pelo qual estas funções não foram utilizadas é 0 alto nível de ruídos presentes nas curvas.

Observa-se nesta figura que, como esperado, existe uma ligeira tendência de diminuição no intervalo de tempo entre as ondas P e Ps conforme se aumenta a distância epicentral. Este "normal move-out" ocorre porque, com 0 aumento desta distância, os ângulos de refração das ondas se aproximam mais da vertical e como conseqüência causarão uma diminuição na distância dos pontos de emergência destas ondas na interface da Moho, e desta maneira 0 intervalo entre 0 tempo de chegada destas ondas diminuirá.

Para aumentar a razão sinal/ruído, foi feito empilhamento das funções com distâncias epicentrais e azimutes semelhantes.

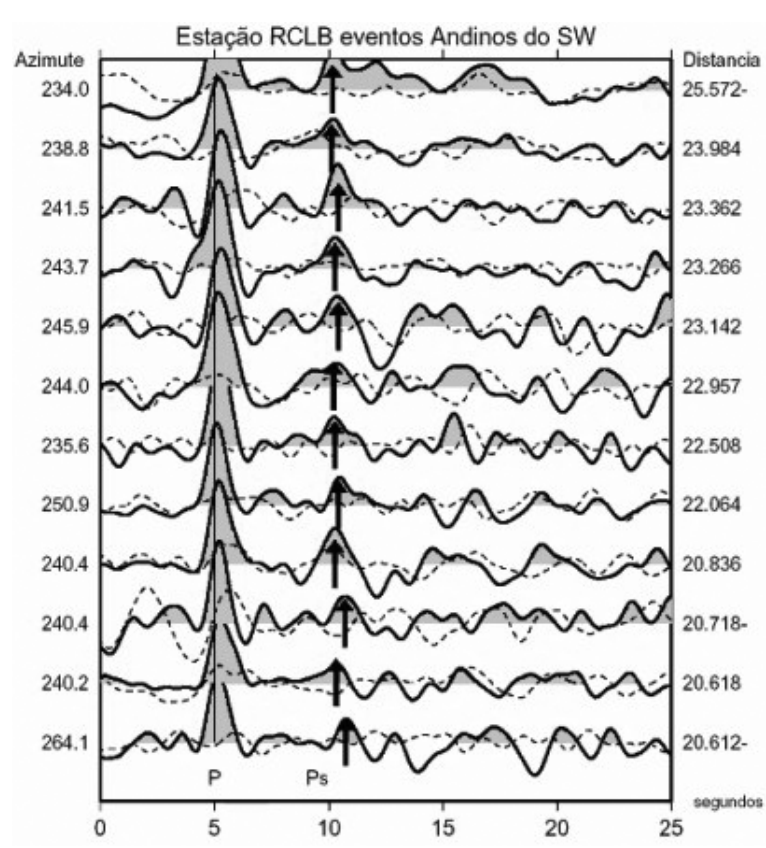

Figura 6 - Curvas de 12 FR com 25 segundos de janela de tempo. A onda direta (P) está alinhada em $5 \mathrm{~s}$. A seta em torno de $10 \mathrm{~s}$ aponta a fase convertida Ps. Em linha sólida estão as FR radiais, com o pico positivo realçado em cinza, com linhas tracejadas estão as FR transversais. 


\section{Análise Azimutal}

Neste trabalho, após analisar a Figura 5, onde se encontram os eventos utilizados para se calcular a função do receptor, foi feito 0 processamento das inversões para os seguintes azimutes e regiões:

- SW - Considerando os eventos Andinos do sudoeste, provenientes do Chile e Argentina, distância de $20^{\circ}$ a $25^{\circ}$.

- WNW - Eventos Andinos do oeste, provenientes do norte do Chile e do Peru, distância de $21^{\circ}$ a $29^{\circ}$.

- NW - Eventos do noroeste, este azimute teve três regiões individualizadas pelas distâncias epicentrais: América Central, México e Califórnia, distância de $44^{\circ}$ a $90^{\circ}$.

- SE - Azimute dos eventos do sudeste, com duas regiões individualizadas, Ilhas South Georgia e South Sandwhich, localizadas no Atlântico Sul.

- E, NE e NNW - Poucos eventos; foram analisados os dados de NE (Norte da África) e NNW (Caribe).

0 agrupamento dos eventos foi feito para tornar 0 empilhamento dos sismogramas e a análise das FRs mais coerentes.

\section{Empilhamento}

0 empilhamento dos traços da função do receptor tem como objetivo diminuir os ruídos ambientais aleatórios, pois o sinal gerado nas estruturas em subsuperfície deve repetir coerentemente.

A Figura 7 mostra como exemplo, os eventos utilizados para se fazer 0 empilhamento dos eventos de SW.

0 critério de empilhar somente os traços de eventos próximos é embasado no fato de que nestas condições o efeito do "normal move out" é desprezível. Nos eventos selecionados para $0 \mathrm{em}$ pilhamento, foram aplicados pesos considerando-se principalmente o nível de ruídos presentes.

A Figura 7 mostra que o resultado do empilhamento evidencia uma melhora na morfologia da $\mathrm{FR}$, deixando inequívoco o pico referente à Ps próximo dos 10 segundos. Para todos os azimutes citados foi feito 0 empilhamento das FR.

Obedecendo-se os critérios citados, foi feito o empilhamento das curvas da função do receptor para todos os azimutes analisados. A Figura 8 mostra as curvas obtidas para a FR Radial e FR Transversal, bem como o número de traços utilizados no empiIhamento.

\section{Modelagem e inversão}

0 processo de inversão é bastante utilizado na análise da função do receptor para fornecer informações mais detalhadas sobre a estrutura crustal. Neste trabalho utilizou-se o procedimento sugerido e descrito por Ammon (1997), no qual a inversão é realizada para 0 parâmetro velocidade cisalhante (calculada a partir da Vp para um valor do Coeficiente de Poisson de 0,25) para uma estrutura de estratos com espessuras fixas.

Para diminuir a ambigüidade, presente em qualquer inversão, as rotinas utilizam o parâmetro de "suavidade" (smoothness) para governar como vai ser 0 ajuste da FR sintética à FR real. Quando maior a aspereza utilizada (menor suavidade), maior vai ser 0 ajuste conseguido e menor a ambigüidade (Ammon, 1997). Porém, na presença de ruídos a maior aspereza poderá gerar um modelo da crosta com grande irregularidade. Por isso, quanto melhor for razão sinal-ruído da FR real, geralmente obtida através de empilhamento de muitos eventos ou através de um evento com uma magnitude muito grande, menor poderá ser a suavidade, caso contrário ela deverá ser escolhida com muito critério para não gerar modelos irreais ou com pouco ajuste nas FR sintéticas.

Para determinar qual a suavidade a ser utilizada neste trabaIho foi feito um processamento com os dados da FR estaqueada do SW, onde 12 inversões de 5 iterações cada foi executada para valores de suavidade variando de 0,0 a 1,1 em passos de 0,1 , conforme procedeu França (2003). A partir da análise das FR e modelos obtidos neste teste, optou-se utilizar um valor de 0,1 como padrão para suavidade, por julgar que ele produz um equilíbrio entre um bom ajuste da FR sintética gerada e um modelo estável.

Para se fazer a inversão é preciso estabelecer um modelo inicial. Para este trabalho optou-se por construir um modelo inicial baseado em Assumpção et al. (2002), considerando-se que os autores compilaram uma grande quantidade de dados do sudeste brasileiro.

No modelo inicial adotado a crosta é constituída de uma camada superficial com $1 \mathrm{~km}$ de espessura e $V p=3,0 \mathrm{~km} / \mathrm{s}$ relacionada aos sedimentos da Bacia do Paraná e mais três camadas com velocidades e densidades crescentes com a profundidade, correspondentes à crosta superior (espessura de $14 \mathrm{~km} \mathrm{e} \mathrm{Vp=}$ 6,20 k/s), intermediária (espessura de $15 \mathrm{~km}$ e Vp =6,60 km/s) e

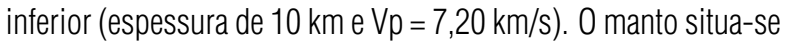
à profundidade de $42 \mathrm{~km}$, com $\mathrm{Vp}=8,0 \mathrm{~km} / \mathrm{s}$.

De posse deste modelo, foram executadas as inversões para todos os azimutes estudados. Apresenta-se como exemplo a inversão obtida para 0 SW, utilizando a FR empilhada. A Figura 9 mostra a FR empilhada (em preto) e FR obtida pela inversão. 


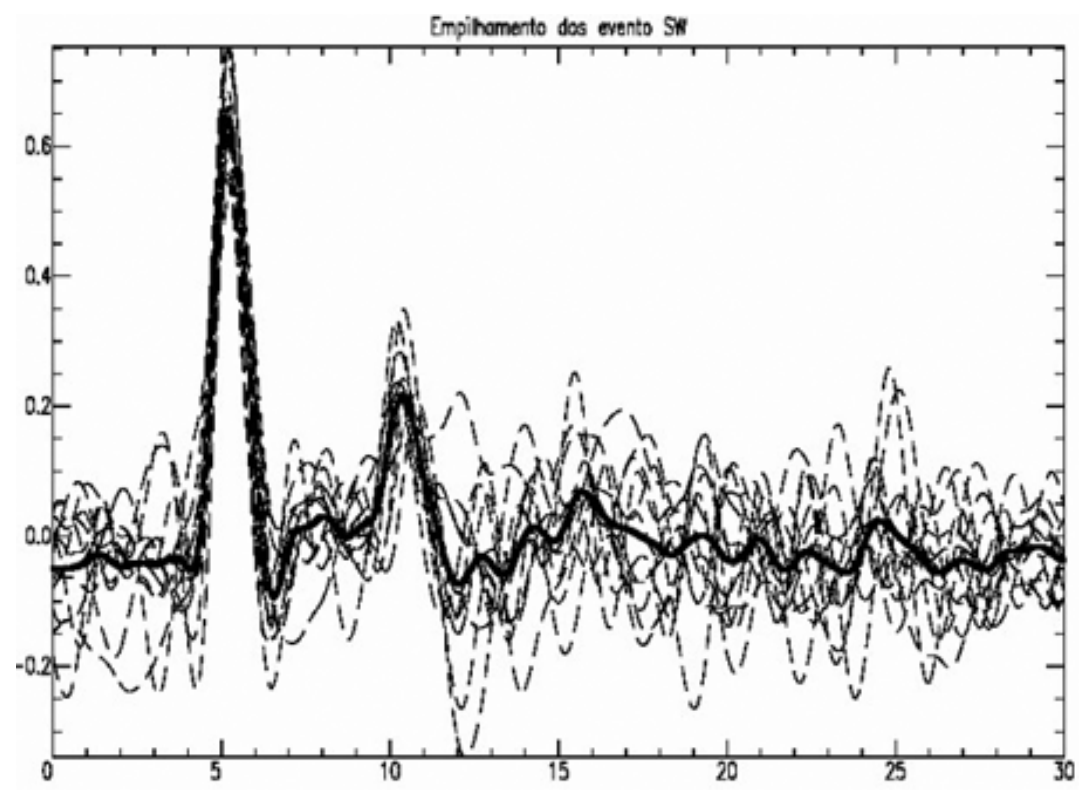

Figura 7 - Função do receptor empilhada para os eventos de SW (linha cheia). Linhas tracejadas são as componentes radiais da Fig. 4. Linha sólida é a FR empilhada resultante.

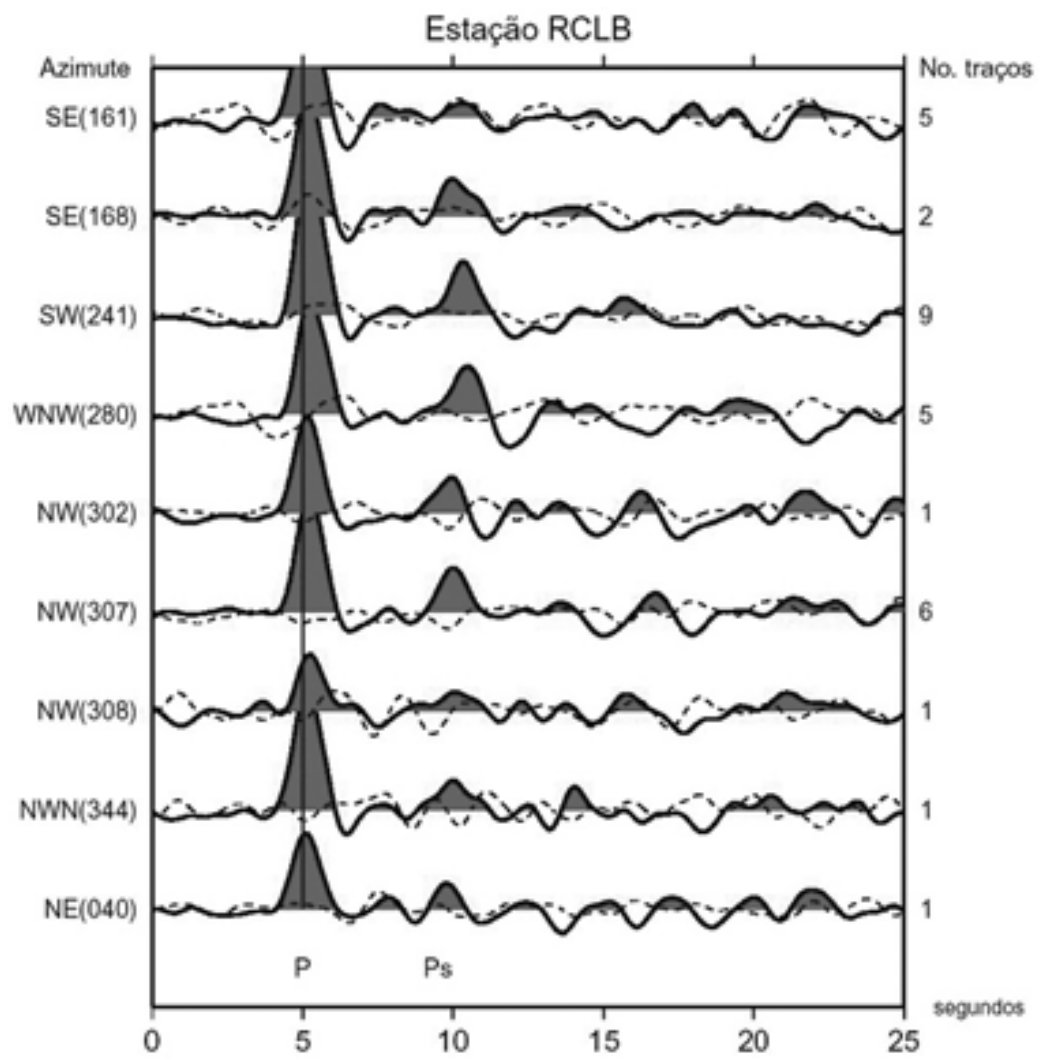

Figura 8 - Função do receptor após empilhamento, FR Radial (linha sólida) e FR Transversal (linha tracejada) distribuída de acordo com o azimute do evento, o número de traços utilizados para o empilhamento está indicado à direita do gráfico. 


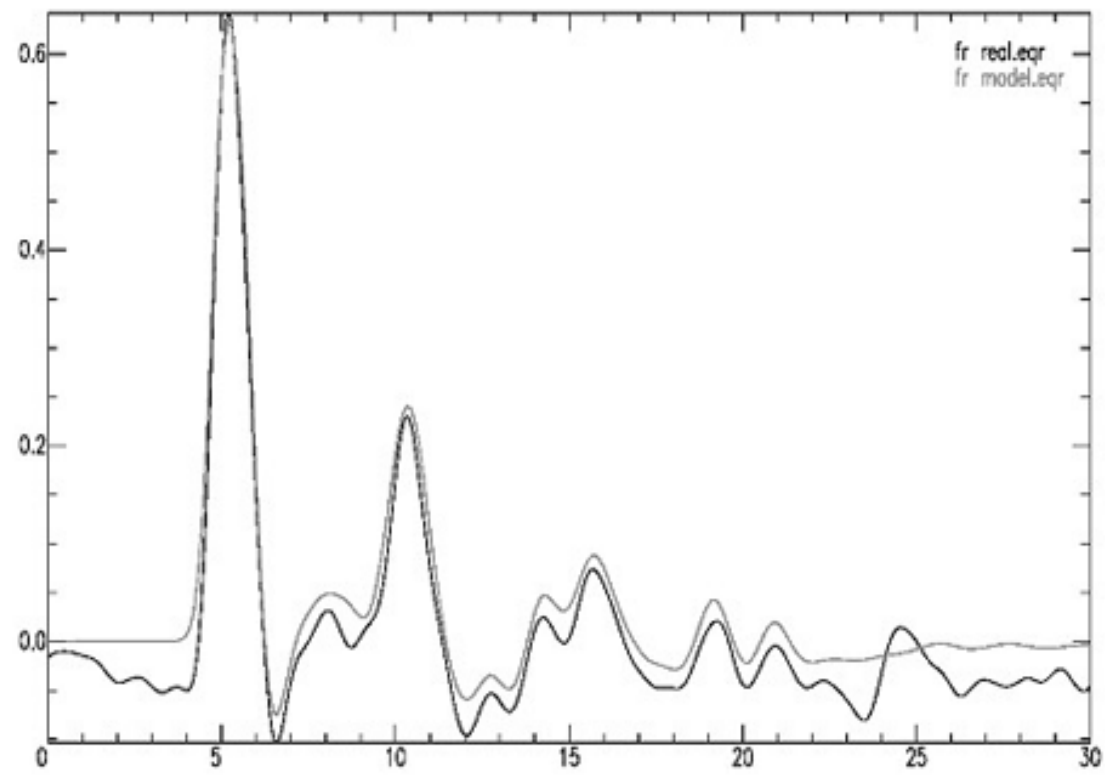

Figura 9 - Comparação entre a FR obtida (preto) e a calculada pelo processo de inversão após a 5 a iteração (cinza). 0 ajuste entre as curvas foi de $85 \%$.

0 fato da FR sintética não se ajustar bem após 22 segundos pode ser causado pela limitação da inversão em $42 \mathrm{~km}$, pois após esse tempo a FR sintética torna-se bastante plana devido à ausência de fases que podem ser geradas pelo modelo com esta profundidade.

Nesta figura também se percebe 0 alongamento da fase $\mathrm{P}$ direta, este alongamento é devido à estação estar locada sobre rochas sedimentares, pois segundo Cassidy (1992), a presença desta camada de baixa velocidade gera uma onda Ps que chega junto da P direta da Moho.

Como exemplos, são mostrados o modelo inicial (em preto) e o modelo da crosta obtido pela inversão da FR (em vermelho) para 0 quadrante SW na Figura 10.

A Figura 11 mostra os modelos obtidos, conforme o procedimento descrito acima para cada azimute analisado. Nesta figura $\mathrm{SE}^{1}$ está relacionado com os eventos próximos às ilhas "South Georgia" e SE ${ }^{2}$ com eventos próximos das ilhas "South Sandwhich". No azimute NW* as três curvas representam os eventos da Califórnia (azul), do México (verde) e América Central (vermelho).

\section{Profundidade da Moho}

De acordo com o tratamento dos dados executados neste trabaIho, pode-se determinar a profundidade da Moho através de duas maneiras. A primeira é calculando-se a profundidade diretamente através da diferença de tempo entre a onda $\mathrm{P}$ e a fase Ps e a outra é analisando-se os modelos de velocidade para a crosta, obtidos na inversão.

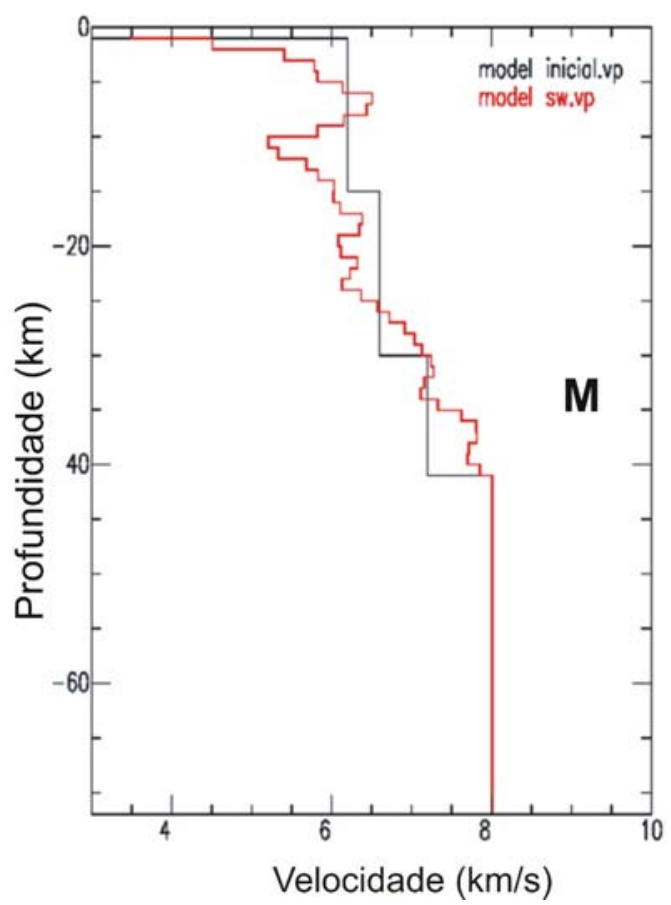

Figura 10 - Inversão do traço empilhado para SW. As ondas P do modelo inicial estão em preto e o modelo obtido em vermelho após o processo de inversão ( $5^{\mathrm{a}}$ iteração). Notar que a interpretação para a profundidade da Moho (letra M) é de aproximadamente $36 \mathrm{~km}$ de profundidade para este azimute. 

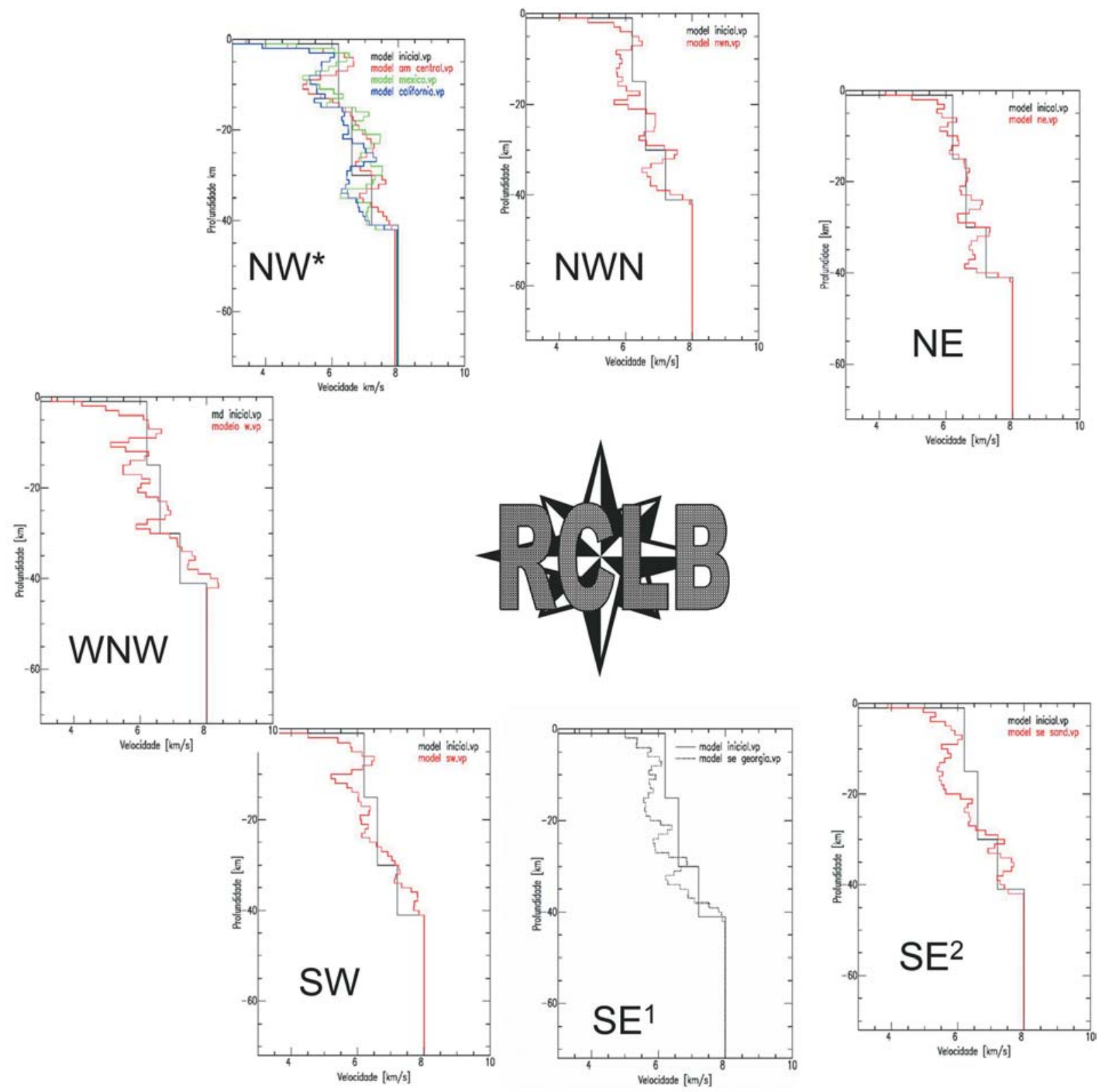

Figura 11 - Modelos de velocidade das ondas P para a crosta, obtidos a partir da inversão das FRs e distribuídas de acordo com o azimute aproximado do evento em relação à Estação Sismológica RCLB. (Representação esquemática sem escala).

Para o primeiro caso foi adotada uma velocidade média de propagação de ondas $P$ no valor de $6,5 \mathrm{~km} / \mathrm{s}$ e uma relação Vp/Vs $=1,732$ e utilizando a seguinte fórmula (Zandt \& Ammon, 1995):

$$
h=\frac{t_{P s}-t_{P}}{\left(V_{s}^{-2}-p^{2}\right)^{1 / 2}-\left(V_{p}^{-2}-p^{2}\right)^{1 / 2}}
$$

Cabe ressaltar que os valores de velocidade são adotados para toda a crosta. Para o segundo caso as velocidades utilizadas são aquelas apresentadas no item anterior.
A Tabela 1 mostra a profundidade calculada para cada azimute estudado, através da média das profundidades dos traços utilizados no empilhamento e também a profundidade que pode ser obtida na inversão, através nos gráficos dos modelos das Figuras 10 e 11.

Onde:

$\mathrm{N}=$ número de eventos utilizados;

$\Delta=$ distância epicentral; 
Tabela 1 - Valores de profundidade da Moho.

\begin{tabular}{|c|c|c|c|c|c|c|c|c|}
\hline Região & N & $\Delta$ (variação) & Azimutes & $p(s / k m)$ & $P s-P(s)$ & $\mathrm{hc}(\mathrm{km})$ & hi (km) & Dif. $\%$ \\
\hline SW & 6 & $20,3^{\circ}-23,9^{\circ}$ & $235,6^{\circ}-245,9^{\circ}$ & 0,095 & 5,22 & 40,7 & 36 & 13,1 \\
\hline WNW & 5 & $22,4^{\circ}-29,6^{\circ}$ & $276^{\circ}-283,4^{\circ}$ & 0,087 & 5,41 & 43,2 & 38 & 13,7 \\
\hline $\mathrm{NW}^{1}$ & 6 & $44,9^{\circ}-51,2^{\circ}$ & $306,1^{\circ}-307,2^{\circ}$ & 0,069 & 5,01 & 41,7 & 42 & $-0,7$ \\
\hline $\mathrm{NW}^{2}$ & 1 & $68,6^{\circ}$ & $302,2^{\circ}$ & 0,056 & 4,97 & 42,3 & 43 & $-1,6$ \\
\hline $\mathrm{NW}^{3}$ & 1 & $90,4^{\circ}$ & $308,6^{\circ}$ & 0,042 & 5,12 & 44,3 & 43 & 3,2 \\
\hline$S E^{1}$ & 5 & $36,29^{\circ}-38,25^{\circ}$ & $160,1^{\circ}-161,8^{\circ}$ & 0,076 & 5,32 & 43,6 & 43 & 1,5 \\
\hline $\mathrm{SE}^{2}$ & 2 & $34,3^{\circ}-34,6^{\circ}$ & $168^{\circ}-168,4^{\circ}$ & 0,078 & 5,02 & 41,0 & 39 & 5,2 \\
\hline $\mathrm{NE}$ & 1 & $76,27^{\circ}$ & $39,9^{\circ}$ & 0,051 & 4,87 & 41,7 & 42 & $-0,6$ \\
\hline NWN & 1 & $41,85^{\circ}$ & $344^{\circ}$ & 0,073 & 5,07 & 41,8 & 42 & $-0,3$ \\
\hline & \multicolumn{5}{|c|}{ Profundidade média em km } & 42,3 & 40,9 & \\
\hline
\end{tabular}

$\mathrm{p}=$ parâmetro do raio;

$\mathrm{Ps}-\mathrm{P}=$ diferença de tempo entre a onda $\mathrm{P}$ e a fase convertida 0 s;

$\mathrm{hc}=$ profundidade calculada diretamente;

hi = velocidade obtida pela inversão;

Dif. = média das diferenças hc-hi;

NW ${ }^{1}=$ eventos provenientes da América Central;

$\mathrm{NW}^{2}=$ eventos provenientes do México;

$\mathrm{NW}^{3}=$ eventos provenientes da Califórnia;

$\mathrm{SE}^{1}=$ eventos provenientes das ilhas South Georgia;

$\mathrm{SE}^{2}=$ eventos provenientes das ilhas South Sandwhich.

\section{DISCUSSÃO DOS RESULTADOS E CONCLUSÕES}

Como mostrado na Tabela 1, as profundidades obtidas através do cálculo utilizando uma velocidade única para toda a crosta diferem daquelas obtidas através do processo de inversão. Essa diferença é diretamente proporcional à variação das velocidades da crosta, ou seja, quando maior a diferença obtida para um azimute, maior deve ser a diferença entre a velocidade média utilizada no cálculo da velocidade média realmente existente na crosta.

Quando esta diferença for positiva indica que as velocidades na crosta para aquela região azimutal considerada devem ser menores do que a adotada para o calculo direto da profundidade, $\mathrm{e}$ vice-versa.

Das regiões azimutais analisadas apenas duas (SW e WNW) tiveram uma diferença maior do que $5 \%$, justamente as que tiveram menor profundidade da Moho, indicando que para estas regiões deve haver uma diferenciação litológica e estrutural maior do que para outros azimutes.

Analisando-se a Figura 11, pode-se constatar que a Moho diminui de profundidade para o quadrante SW.
Outro dado que pode ser utilizado para corroborar com esta constatação é a análise da função do receptor transversal, representada pela linha tracejada na Figura 8. De acordo com Peng \& Humphreys (1997) para uma Moho inclinada para o rumo NE, a FR transversal terá o pico da P negativo para os eventos vindo dos azimutes localizados a NW e positivo para eventos dos azimutes SE. Este fato realmente ocorre nos traços dos azimutes NW e SE mostrados na Figura 6.

De acordo ainda com os autores, os picos referentes Ps terão sinal invertido em relação aos picos da $\mathrm{P}$ na $F R$ transversal. Porém os picos desta fase não aparecem com clareza nos traços obtidos, isto pode ter ocorrido pela baixa relação sinal/ruído desta fase.

Outra avaliação que pode ser feita na análise da Figura 11 é a existência de uma variação muito grande de velocidade na crosta, mostrando inclusive inversões de velocidade em todos os azimutes.

Para melhor visualização desta variação foi construído um bloco 3D utilizando-se os modelos obtidos para cada azimute e mostrado na Figura 12. Este bloco foi feito a partir de um prisma quadrado, cuja base tem aproximadamente $25 \mathrm{~km}$ de lado ( $\left.\sim 1^{\prime}\right)$ e altura de $42 \mathrm{~km}$, com a estação RCLB colocada no centro da face superior. Os modelos obtidos foram colocados nas correspondentes direções azimutais em relação à estação e a partir destes dados foram gerados grides de slices a cada $1 \mathrm{~km}$ de profundidade.

Analisando-se a morfologia dos modelos mostrados na Figura 9 e 0 perfil da Figura 10, nota-se a existência de alternância entre velocidade baixa (cinza claro) com velocidade alta (cinza escuro), acusando inversões de velocidade com a profundidade. 


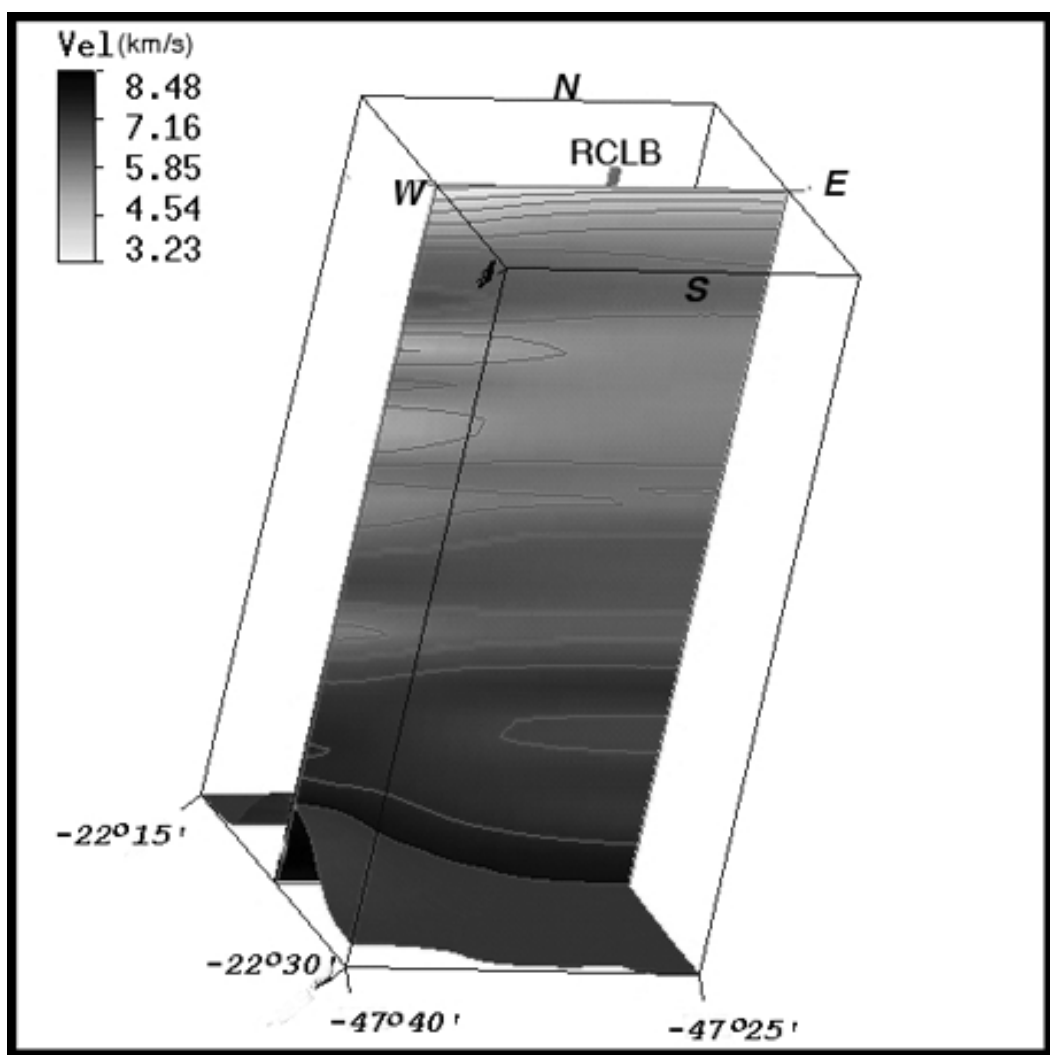

Figura 12 - Visada SW do bloco 3D representando um perfil da crosta no sentido W-E passando pela estação RCLB. Superfície inferior representa os isovalores para a velocidade de $8 \mathrm{~km} / \mathrm{s}$, ou seja, equivalente à interface crosta-manto.

A inversão de velocidade é indicativa de uma grande heterogeneidade lito-estrutural da crosta que pode ser causada inclusive por duplicação da crosta inferior, fenômeno que ocorre com freqüência nas zonas de sutura. Esta situação ocorre em região de convergência de placas tectônicas, onde se tem uma elevação da crosta inferior da placa que se sobrepõe, por cavalgamento, à placa mergulhante (Kröner, 1984).

No entanto, além da possibilidade de ter sido causada pela zona de sutura, esta heterogeneidade da crosta nesta região pode ter sido consequiência da grande complexidade estrutural presente. De acordo com a bibliografia. três grandes alinhamentos estruturais estão se cruzando na área da RCLB, são eles: os Alinhamentos Estruturais do Tietê e do Rio Moji-Guaçu (Riccomini, 1997), e a Zona de Falha de Jacutinga (Zalan et al., 1990).

Os alinhamentos estruturais do Tietê e Moji-Guaçu, segundo Riccomini (1997), são feições que mantém relações com estruturas do embasamento e que atuaram durante toda a sedimentação do Grupo Bauru, inclusive influenciando no aparecimento dos altos estruturais que ocorrem na junção dos dois alinhamentos e que é representado na área pelo Domo de Pitanga.

A Zona de Falha de Jacutinga foi determinado sob os sedimentos da Bacia do Paraná através de um lineamento gravimétrico do embasamento (Quintas, 1995). Este alinhamento separa blocos com variações de anomalia com forte gradiente, sendo que a NW o bloco com anomalias positivas e SE com anomalias negativas.

Já 0 comportamento da Moho, mostrada pela superfície da Figura 12, indica que existe uma tendência de subida da interface crosta-manto na direção do alto estrutural do Domo de Pitanga, pois como mostra o mapa geológico local (Fig. 13) o Domo está localizado justamente sobre as feições "altas" da Moho, indicando que esta estrutura pode ter relações com a interface crosta-manto.

Não se deve descartar a possibilidade que esta elevação da Moho pode estar associada aos grandes eventos magmáticos do Mesozóico.

Os dados sobre a profundidade e comportamento da Moho para esta área é inédito e deverá contribuir para 0 estudo a evolução geológica. 


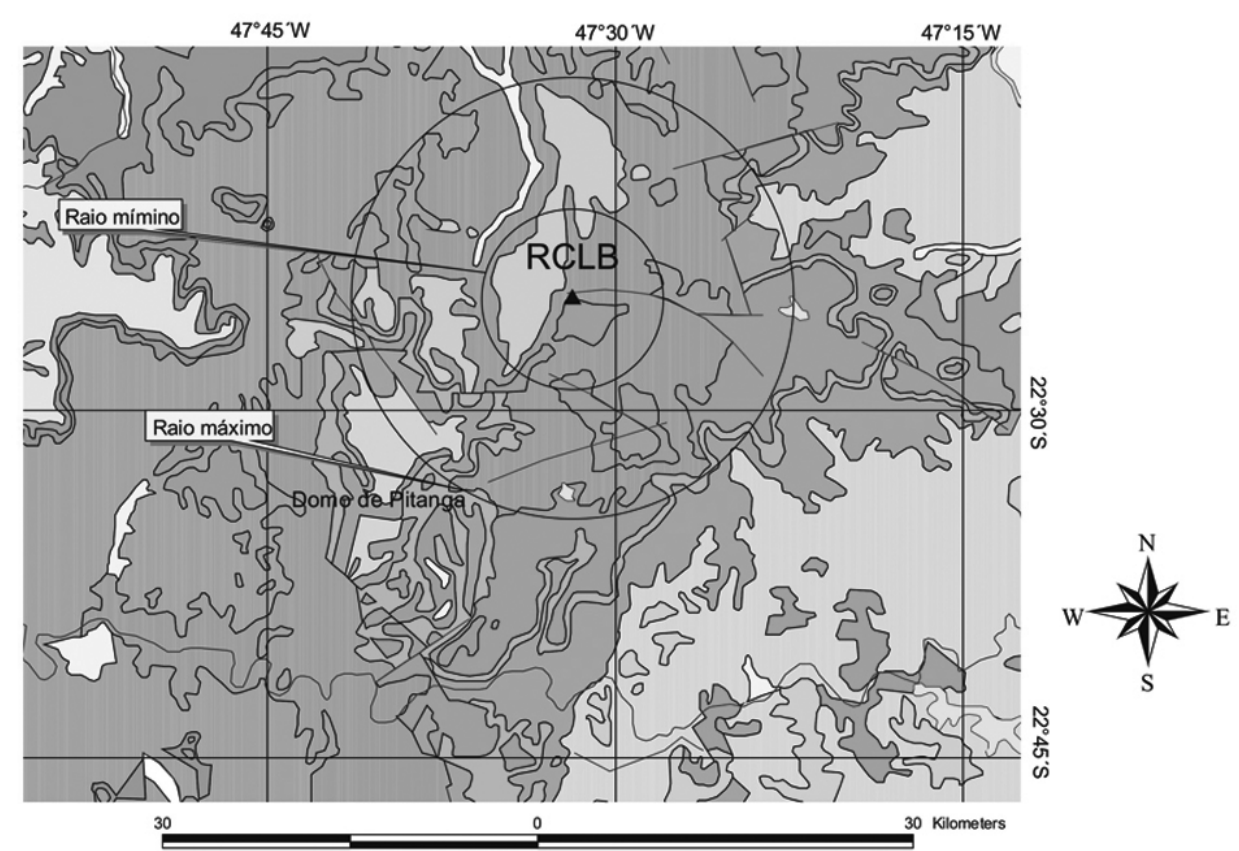

Figura 13 - Mapa geológico local (CPRM, 2001) mostrando em planta a auréola de emergência dos raios das ondas P na Moho, para os eventos utilizados no cálculo da função do receptor neste trabalho. 0 raio mínimo possui aproximadamente 6,7 km e 0 raio máximo 16,4 km. Esses raios foram determinados de acordo com Ammon (1997). Notar a localização do alto estrutural (Domo de Pitanga) à SW da RCLB.

\section{AGRADECIMENTOS}

Os autores agradecem à FAPESP pelo apoio financeiro ao projeto (Proc. 01/05515-1) e aos técnicos José Roberto Barbosa (IAG-USP) e Francisco Manuel Garcia Barrera (ICGE-UNESP) pelo apoio na instalação e manutenção da estação sismológica. Os gráficos da função do receptor foram executados com GMT (Wessel \& Smith, 1991) e os sismogramas e modelos foram feitos com o programa SAC (Tapley \& Tull, 1991).

\section{REFERÊNCIAS}

AMMON CJ. 1997. An overview of Receiver-Function Analysis. Disponível em: <http://quake.eas.slu.edu/People/CJAmmon-/HTML/RftnDocs/ rftn01.html >. Acesso em: 10 ago. 2004.

ASSUMPÇÃO M, JAMES D \& SNOKE JA. 2002. Crustal thicknesses in SE Brazilian shield by receiver function analysis: implications for isostatic compensation. J. Geophys. Res., 107, doi:10.1029/2001JB000422, ese2-14p.

CASSIDY JF. 1992. Numerical experiments in broadband receiver analysis. Bull. Seism. Soc. Am., 82: 1453-1474.

CPRM. Companhia de Pesquisa de Recursos Minerais. 2001. Geologia, Tectônica e Recursos Minerais do Brasil: Sistema de Informações Geográficas - SIG e Mapas na escala 1:2.500.000 / Luiz Augusto Bizzi,
Carlos Schobbenhaus, João Henrique Gonçalves, Franciscus Jacobus Baars, Inácio de Medeiros Delgado, Maísa Bastos Abram, Reginaldo Leão Neto, Gerson Manoel Muniz de Matos, João Orestes Schneider Santos Brasilia: CPRM, 2001. 4 CD-ROM.

FRANÇA GSLA. 2003. Estrutura da crosta no Sudeste e Centro-Oeste do Brasil, usando função do receptor. Tese (Doutorado em Geofísica). Instituto de Astronomia, Geofísica e Ciências Atmosféricas da USP, São Paulo. 143f.

JULIÀ J, AMMON CJ, HERRMANN RB \& AKINCI A. 2003. Lithospheric structure of the Arabian Shield from the joint inversion of receiver functions and surface-wave group velocities. Tectonophysics, 371: 1-21.

KRÖNER A. 1984. Evolution, growth and stabilization of the Precambrian lithosphere. In: POLLACK HN \& MURTHY VR (Ed.). Physics and chemistry of the Earth. Pergamon, 15: 69-108.

LANGSTON CA. 1977. The effect of planar dipping structure on source and receiver responses for constant ray parameter. Bull. Seism. Soc. Am., 67: 1029-1050.

LANGSTON CA. 1979. Structure under Mount Rainier, Washington, inferred from teleseismic body waves. J. Geophys. Res., 84: 4749-4762.

PENG X \& HUMPHREYS ED. 1997. Moho dip and crustal anisotropy in northwestern Nevada from teleseismic receiver functions. Bull. Seism. Soc. Am., 87(3): 745-754. 
QUINTAS MCL. 1995. 0 embasamento da Bacia do Paraná: reconstrução geofísica do seu arcabouço. Tese (Doutorado em Geofísica). Instituto Astronômico e Geofísico, Universidade de São Paulo, São Paulo. 213 f.

RICCOMINI C. 1997. Arcabouço estrutural e aspectos do tectonismo gerador e deformador da Bacia Bauru no Estado de São Paulo. Revista Brasileira de Geociências, 27 (2): 153-162.

SOUSA MOL. 1997. Caracterização estrutural do Domo de Pitanga - SP. Dissertação de Mestrado em Geociências - Instituto de Geociências e Ciências Exatas - UNESP, Rio Claro. $116 f$.

SOUSA MOL. 2002. Evolução tectônica dos Altos Estruturais de Pitanga, Artemis, Pau D'Alho e Jibóia, Centro do Estado de São Paulo. Tese (Doutorado em Geociências), Instituto de Geociências e Ciências Exa- tas, Universidade Estadual Paulista, Rio Claro. 206 f.

TAPLEY WC \& TULL JE. 1991. SAC - Seismic Analysis Code - User Manual. Mail Stop L-205, Livermore, CA, 94550, July.

WESSEL P \& SMITH WHF. 1991. Free software helps map and display data: Eos Trans. AGU, 72(441): 445-446.

ZALAN PV, WOLFF S, CONCEIÇÃO JC, MARQUES A, ASTOLFI MAM, VIEIRA IS \& APPI VT. 1990. Bacia do Paraná. In: RAJA GABAGLIA GP \& MILANI EJ (Ed.). Origem e evolução de bacias sedimentares. Rio de Janeiro, PETROBRAS, p. 135-164.

ZANDT GS \& AMMON CJ. 1995. Continental crust composition constrained by measurements of crustal Poisson's ratio. Nature, 374: 152-154.

\section{NOTAS SOBRE OS AUTORES}

João Carlos Dourado. Geólogo pelo Instituto de Geociências da USP (1977). Trabalhou como geofísico no Instituto de Pesquisas Tecnológicas de 1978 a 1997 com métodos de prospecção geofísicas rasas (principalmente sísmicos e elétricos). Desde 1997 é docente do Departamento de Geologia Aplicada da UNESP, livre-docente na disciplina Geofísica Aplicada. As atuais áreas de atuação são: geofísica aplicada, geofísica regional com ênfase em sismologia.

Marcelo Assumpção. Graduado em Física (USP, 1973) e Geofísica (Edinburgh University, 1978) é professor titular do IAG-USP. Trabalhou no Observatório Sismológico da Universidade de Brasília de 1982 a 1988. Suas principais áreas de pesquisa são: sismicidade do Brasil (sismos naturais e induzidos, tensões intraplaca, e risco sísmico), e estrutura da crosta e manto superior (função do receptor e espessura da crosta, tomografia do manto superior, anisotropia sísmica da litosfera e geodinâmica).

Walter Malagutti Filho. Bacharel em geologia pela UNESP em 1980. Geólogo do Agrupamento de Geofísica do Instituto de Pesquisas Tecnológicas de 1981 a 1986. Docente do Departamento de Geologia Aplicada da UNESP, livre-docente na disciplina Geofísica Aplicada. Atua nas áreas da Geofísica Aplicada e Geofísica Regional.

Marcelo Belentani de Bianchi. Aluno de pós-graduação do IAG/USP onde desde o período de sua graduação em 2000 vem participando e colaborando com os trabalhos realizados dentro do laboratório de sismologia da USP. Iniciou na área de sismologia como aluno de iniciação científica em projetos de determinação epicentral e estudos da crosta através da função do receptor. Começou seu doutorado 2004, quando iniciou o seu projeto sobre tomografia de atenuação sísmica na plataforma Sul-Americana. As suas maiores áreas de interesse são sismologia, tectônica e comportamento do manto terrestre. 